\title{
Certain Types of Interval-Valued Fuzzy Graphs
}

\author{
Muhammad Akram, ${ }^{1}$ Noura Omair Alshehri, ${ }^{2}$ and Wieslaw A. Dudek ${ }^{3}$ \\ ${ }^{1}$ Punjab University College of Information Technology, University of the Punjab, Old Campus, Lahore 54000, Pakistan \\ ${ }^{2}$ Department of Mathematics, Faculty of Sciences (Girls), King Abdulaziz University, Jeddah, Saudi Arabia \\ ${ }^{3}$ Institute of Mathematics and Computer Science, Wroclaw University of Technology, Wybrzeze Wyspianskiego 27, \\ 50-370 Wroclaw, Poland \\ Correspondence should be addressed to Noura Omair Alshehri; nalshehrie@kau.edu.sa
}

Received 29 July 2013; Accepted 31 August 2013

Academic Editor: Chong Lin

Copyright ( 2013 Muhammad Akram et al. This is an open access article distributed under the Creative Commons Attribution License, which permits unrestricted use, distribution, and reproduction in any medium, provided the original work is properly cited.

We propose certain types of interval-valued fuzzy graphs including balanced interval-valued fuzzy graphs, neighbourly irregular interval-valued fuzzy graphs, neighbourly total irregular interval-valued fuzzy graphs, highly irregular interval-valued fuzzy graphs, and highly total irregular interval-valued fuzzy graphs. Some interesting properties associated with these new interval-valued fuzzy graphs are investigated, and necessary and sufficient conditions under which neighbourly irregular and highly irregular intervalvalued fuzzy graphs are equivalent are obtained. We also describe the relationship between intuitionistic fuzzy graphs and intervalvalued fuzzy graphs.

\section{Introduction}

The major role of graph theory in computer applications is the development of graph algorithms. A number of algorithms are used to solve problems that are modeled in the form of graphs. These algorithms are used to solve the graph theoretical concepts, which in turn are used to solve the corresponding computer science application problems. Several computer programming languages support the graph theory concepts [1]. The main goal of such languages is to enable the user to formulate operations on graphs in a compact and natural manner. Some of these languages are (1) SPANTREE: to find a spanning tree in the given graph, (2) GTPL: graph theoretic language, (3) GASP: graph algorithm software package, (4) HINT: an extension of LISP, (5) GRASPE: an extension of LISP, (6) IGTS: an extension of FORTRAN, (7) GEA: graphic extended AL-GOL, (8) AMBIT: to manipulate digraphs, (9) GIRL: graph information retrieval language, and (10) FGRAAL: FORTRAN Extended graph algorithmic language $[1,2]$.

Zadeh [3] introduced the notion of interval-valued fuzzy sets, and Atanassov [4] introduced the concept of intuitionistic fuzzy sets as extensions of Zadeh's fuzzy set theory [5] for representing vagueness and uncertainty. Interval-valued fuzzy set theory reflects the uncertainty by the length of the interval membership degree $\left[\mu_{1}, \mu_{2}\right]$. In intuitionistic fuzzy set theory for every membership degree $\left(\mu_{1}, \mu_{2}\right)$, the value $\pi=1-\mu_{1}-\mu_{2}$ denotes a measure of nondeterminacy (or undecidedness). Interval-valued fuzzy sets provide a more adequate description of vagueness than traditional fuzzy sets. It is therefore important to use interval-valued fuzzy sets in applications, such as fuzzy control. One of the computationally most intensive parts of fuzzy control is defuzzification [6]. Since interval-valued fuzzy sets are widely studied and used, we describe briefly the work of Gorzalczany on approximate reasoning $[7,8]$, Roy and Biswas on medical diagnosis [9], Türksen on multivalued logic [10], and Mendel on intelligent control [6].

Kauffman's initial definition of a fuzzy graph [11] was based on Zadeh's fuzzy relations [5]. Rosenfeld [12] introduced the fuzzy analogue of several basic graph-theoretic concepts. Since then, fuzzy graph theory has been finding an increasing number of applications in modeling real time systems where the level of information inherent in the system varies with differences levels of precision. Fuzzy models are becoming useful because of their aim to reduce the 
differences between the traditional numerical models used in engineering and sciences and the symbolic models used in expert systems. Mordeson and Peng [13] defined the concept of complement of fuzzy graph and described some operations on fuzzy graphs. In [14], the definition of complement of a fuzzy graph was modified so that the complement of the complement is the original fuzzy graph, which agrees with the crisp graph case. Ju and Wang gave the definition of intervalvalued fuzzy graph in [15]. Akram et al. [16-20] introduced many new concepts including bipolar fuzzy graphs, intervalvalued line fuzzy graphs, and strong intuitionistic fuzzy graphs. In this paper, we propose certain types of intervalvalued fuzzy graphs including balanced interval-valued fuzzy graphs, neighbourly irregular interval-valued fuzzy graphs, neighbourly total irregular interval-valued fuzzy graphs, highly irregular interval-valued fuzzy graphs, and highly total irregular interval-valued fuzzy graphs. Some interesting properties associated with these new interval-valued fuzzy graphs are investigated, and necessary and sufficient conditions under which neighbourly irregular and highly irregular interval-valued fuzzy graphs are equivalent are obtained. We also describe the relationship between intuitionistic fuzzy graphs and interval-valued fuzzy graphs.

We used standard definitions and terminologies in this paper. For notations, terminologies and applications are not mentioned in the paper; the readers are referred to $[13,14,21-$ 29].

\section{Preliminaries}

In this section, we review some elementary concepts whose understanding is necessary to fully benefit from this paper.

By a graph $G^{*}=(V, E)$, we mean a nontrivial, finite, connected, and undirected graph without loops or multiple edges. We write $x y \in E$ to mean $(x, y) \in E$, and if $e=x y \in E$, we say that $x$ and $y$ are adjacent. Formally, given a graph $G^{*}=(V, E)$, two vertices $x, y \in V$ are said to be neighbors, or adjacent nodes, if $x y \in E$. The number of vertices, the cardinality of $V$, is called the order of graph and denoted by $|V|$. The number of edges, the cardinality of $E$, is called the size of graph and denoted by $|E|$. A path in a graph $G^{*}$ is an alternating sequence of vertices and edges $v_{0}, e_{1}, v_{1}$, $e_{2}, \ldots, v_{n-1}, e_{n}, v_{n}$. The path graph with $n$ vertices is denoted by $P_{n}$. A path is sometimes denoted by $P_{n}: v_{0} v_{1} \cdots v_{n}(n>0)$. The length of a path $P_{n}$ in $G^{*}$ is $n$. A path $P_{n}: v_{0} v_{1} \cdots v_{n}$ in $G^{*}$ is called a cycle if $v_{0}=v_{n}$ and $n \geq 3$. Note that path graph, $P_{n}$, has $n-1$ edges and can be obtained from a cycle graph, $C_{n}$, by removing any edge. An undirected graph $G^{*}$ is connected if there is a path between each pair of distinct vertices. The neighbourhood of a vertex $v$ in a graph $G^{*}$ is the induced subgraph of $G^{*}$ consisting of all vertices adjacent to $v$ and all edges connecting two such vertices. The neighbourhood is often denoted $N(v)$. The degree $\operatorname{deg}(v)$ of vertex $v$ is the number of edges incident on $v$ or equivalently, $\operatorname{deg}(v)=$ $|N(v)|$. The set of neighbors, called a (open) neighborhood $N(v)$ for a vertex $v$ in a graph $G^{*}$, consists of all vertices adjacent to $v$ but not including $v$; that is, $N(v)=\{u \in V \mid v u \in$ $E$. When $v$ is also included, it is called a closed neighborhood $N[v]$, that is, $N[v]=N(v) \cup\{v\}$. A regular graph is a graph where each vertex has the same number of neighbors, that is, all the vertices have the same closed neighbourhood degree. A connected graph is highly irregular if each of its vertices is adjacent only to vertices with distinct degrees. Equivalently, a graph $G^{*}$ is highly irregular if every two vertices of $G^{*}$ connected by a path of length 2 have distinct degrees. A connected graph is said to be neighbourly irregular if no two adjacent vertices of $G^{*}$ have the same degree. Equivalently, a connected graph $G^{*}$ is called neighbourly irregular if every two adjacent vertices of $G^{*}$ have distinct degree.

It is known that one of the best known classes of graphs is the class of regular graphs. These graphs have been studied extensively in various contexts. Regular graphs of degree $r$ and order $n$ exist with only limited, but natural, restrictions. Indeed, for integers $r$ and $n$ with $0 \leq r \leq n-1$, an $r$-regular graph of order $n$ exists if and only if $n r$ is even. A graph that is not regular will be called irregular. It is well known [30] that all nontrivial graphs, regular or irregular, must contain at least two vertices of the same degree. In a regular graph, of course, every vertex is adjacent only to vertices having the same degree. On the other hand, it is possible for a vertex in an irregular graph to be adjacent only to vertices with distinct degrees. With these observations made, we now consider graphs that are opposite, in a certain sense, to regular graphs. We consider only undirected graphs with the finite number of vertices and edges.

Applications of fuzzy relations are widespread and important, especially in the field of clustering analysis, neural networks, computer networks, pattern recognition, decision making, and expert systems. In each of these, the basic mathematical structure is that of a fuzzy graph.

Definition 1 (see $[3,5])$. A fuzzy subset $\mu$ on a set $X$ is a map $\mu: X \rightarrow[0,1]$. A fuzzy binary relation on $X$ is a fuzzy subset $\mu$ on $X \times X$. By a fuzzy relation, we mean a fuzzy binary relation given by $\mu: X \times X \rightarrow[0,1]$.

Fuzzy set theory is an extension of ordinary set theory in which to each element a real number between 0 and 1 , called the membership degree, is assigned. Unfortunately, it is not always possible to give an exact degree of membership. There can be uncertainty about the membership degree because of lack of knowledge, vague information, and so forth. A possible way to overcome this problem is to use interval-valued fuzzy sets, which assign to each element a closed interval which approximates the "real," but unknown, membership degree. The length of this interval is a measure for the uncertainty about the membership degree.

An interval number $D$ is an interval $\left[a^{-}, a^{+}\right]$with $0 \leq a^{-} \leq$ $a^{+} \leq 1$. The interval $[a, a]$ is identified with the number $a \in$ $[0,1]$. Let $D[0,1]$ be the set of all closed subintervals of $[0,1]$. Then, it is known that $(D[0,1], \leq, \vee, \wedge)$ is a complete lattice with $[0,0]$ as the least element and $[1,1]$ as the greatest.

Definition 2 (see [7]). An interval-valued fuzzy relation $R$ in a universe $X \times Y$ is a mapping $R: X \times Y \rightarrow D[0,1]$ such that $R(x, y)=\left[R^{-}(x, y), R^{+}(x, y)\right] \in D[0,1]$ for all pairs $(x, y) \in$ $X \times Y$. 
Interval-valued fuzzy relations reflect the idea that membership grades are often not precise and the intervals represent such uncertainty.

Definition 3 (see [15]). By an interval-valued fuzzy graph $G$ of a graph $G^{*}$, we mean a pair $G=(A, B)$, where $A=\left[\mu_{A}^{-}, \mu_{A}^{+}\right]$ is an interval-valued fuzzy set on $V$ and $B=\left[\mu_{B}^{-}, \mu_{B}^{+}\right]$is an interval-valued fuzzy relation on $E$ such that

$$
\begin{aligned}
& \mu_{B}^{-}(x y) \leq \min \left(\mu_{A}^{-}(x), \mu_{A}^{-}(y)\right), \\
& \mu_{B}^{+}(x y) \leq \min \left(\mu_{A}^{+}(x), \mu_{A}^{+}(y)\right),
\end{aligned}
$$

for all $x y \in E$.

Throughout this paper, $G^{*}$ is a crisp graph, and $G$ is an interval-valued fuzzy graph.

\section{Balanced Interval-Valued Fuzzy Graphs}

Definition 4. Let $G$ be an interval-valued fuzzy graph. The neighbourhood degree of a vertex $x$ in $G$ is defined by $\operatorname{deg}(x)=$ $\left[\operatorname{deg}_{\mu^{-}}(x), \operatorname{deg}_{\mu^{+}}(x)\right]$, where $\operatorname{deg}_{\mu^{-}}(x)=\sum_{y \in N(x)} \mu_{A}^{-}(y)$ and $\operatorname{deg}_{\mu^{+}}(x)=\sum_{y \in N(x)} \mu_{A}^{+}(y)$. Notice that $\mu_{B}^{-}(x y)>0, \mu_{B}^{+}(x y)>$ 0 for $x y \in E$, and $\mu_{B}^{-}(x y)=\mu_{B}^{+}(x y)=0$ for $x y \notin E$.

Definition 5. Let $G=(A, B)$ be an interval-valued fuzzy graph on $G^{*}$. If all the vertices have the same open neighbourhood degree $n$, then $G$ is called an $n$-regular interval-valued fuzzy graph. The open neighbourhood degree of a vertex $x$ in $G$ is defined by $\operatorname{deg}(x)=\left[\operatorname{deg}_{\mu^{-}}(x), \operatorname{deg}_{\mu^{+}}(x)\right]$, where $\operatorname{deg}_{\mu^{-}}(x)=\sum_{y \in N(x)} \mu_{A}^{-}(y)$ and $\operatorname{deg}_{\mu^{+}}(x)=\sum_{y \in N(x)} \mu_{A}^{+}(y)$.

Definition 6. Let $G$ be an interval-valued fuzzy graph. The closed neighbourhood degree of a vertex $x$ is defined by $\operatorname{deg}[x]=\left[\operatorname{deg}_{\mu^{-}}[x], \operatorname{deg}_{\mu^{+}}[x]\right]$, where

$$
\begin{aligned}
& \operatorname{deg}_{\mu^{-}}[x]=\operatorname{deg}_{\mu^{-}}(x)+\mu_{A}^{-}(x), \\
& \operatorname{deg}_{\mu^{+}}[x]=\operatorname{deg}_{\mu^{+}}(x)+\mu_{A}^{+}(x) .
\end{aligned}
$$

If all the vertices have the same closed neighbourhood degree $m$, then $G$ is called a $m$-totally regular interval-valued fuzzy graph.

Example 7. Consider a graph $G^{*}$ such that $V=\{a, b, c, d\}$, $E=\{a b, b c, c d, a d\}$. Let $A$ be an interval-valued fuzzy subset of $V$, and let $B$ be an interval-valued fuzzy subset of $E \subseteq V \times V$ defined by

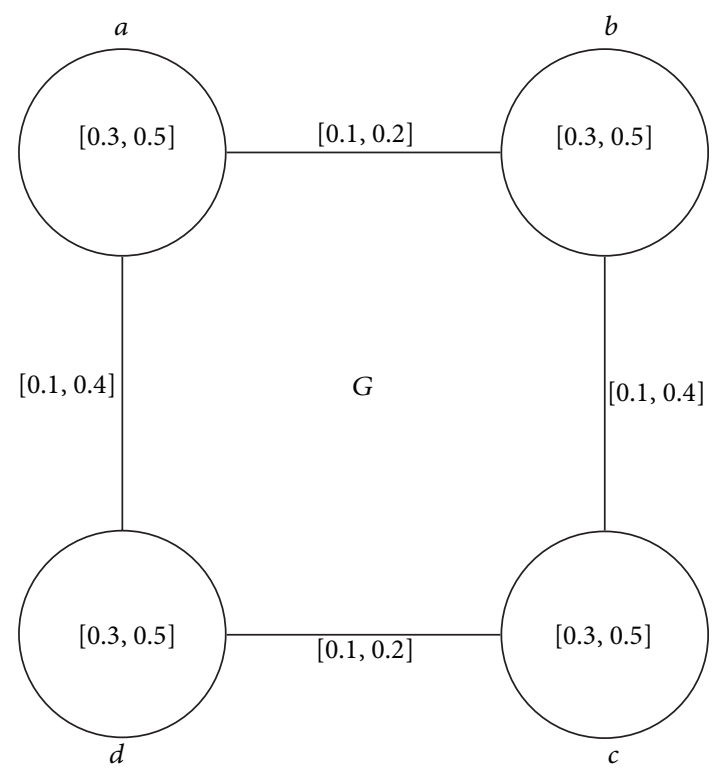

FIGURE 1: $G$ is regular and totally regular.

$$
\left[\begin{array}{c|cccc} 
& a b & b c & c d & d a \\
\hline \mu_{B}^{-} & 0.1 & 0.1 & 0.1 & 0.1 \\
\mu_{B}^{+} & 0.2 & 0.4 & 0.2 & 0.4
\end{array}\right]
$$

Routine computations show that an interval-valued fuzzy graph $G$ as shown in Figure 1 is both regular and totally regular.

Example 8. Consider a graph $G^{*}$ such that $V=\left\{v_{1}, v_{2}, v_{3}\right\}$, $E=\left\{v_{1} v_{2}, v_{1} v_{3}\right\}$. Let $A$ be an interval-valued fuzzy subset of $V$ and let $B$ be an interval-valued fuzzy subset of $E$ defined by

$$
\begin{array}{rlrl}
\mu_{A}^{-}\left(v_{1}\right)=0.4, & \mu_{A}^{-}\left(v_{2}\right)=0.7, & \mu_{A}^{-}\left(v_{3}\right)=0.6, \\
\mu_{A}^{+}\left(v_{1}\right)=0.4, & \mu_{A}^{+}\left(v_{2}\right)=0.8, & \mu_{A}^{+}\left(v_{3}\right)=0.7, \\
\mu_{B}^{-}\left(v_{1} v_{2}\right)=0.2, & \mu_{B}^{-}\left(v_{1} v_{3}\right)=0.2 ; & \mu_{B}^{+}\left(v_{1} v_{2}\right)=0.3, \\
\mu_{B}^{+}\left(v_{1} v_{3}\right)=0.4 . &
\end{array}
$$

Routine computations show that an interval-valued fuzzy graph $G$ is neither totally regular nor regular.

Definition 9. We define the order $O(G)$ and size $S(G)$ of an interval-valued fuzzy graph $G=(A, B)$ by

$$
\begin{gathered}
O(G)=\sum_{x \in V} \frac{1+\mu_{A}^{+}(x)-\mu_{A}^{-}(x)}{2}, \\
S(G)=\sum_{x y \in E} \frac{1+\mu_{B}^{+}(x y)-\mu_{B}^{-}(x y)}{2} .
\end{gathered}
$$


Definition 10. An interval-valued fuzzy graph $G=(A, B)$ is called complete if

$$
\begin{aligned}
& \mu_{B}^{-}(x y)=\min \left(\mu_{A}^{-}(x), \mu_{A}^{-}(y)\right), \\
& \mu_{B}^{+}(x y)=\max \left(\mu_{A}^{+}(x), \mu_{A}^{+}(y)\right) \quad \forall x, y \in V .
\end{aligned}
$$

Example 11. Consider a graph $G^{*}$ such that $V=\{x, y, z\}, E=$ $\{x y, y z, z x\}$. Let $A$ be an interval-valued fuzzy subset of $V$ and let $B$ be an interval-valued fuzzy subset of $E$ defined by

$$
\begin{array}{rlrl}
\mu_{A}^{-}(x) & =0.3, & \mu_{A}^{-}(y)=0.4, & \mu_{A}^{-}(z)=0.5, \\
\mu_{A}^{+}(x)=0.5, & \mu_{A}^{+}(y)=0.7, & \mu_{A}^{+}(z)=0.6, \\
\mu_{B}^{-}(x y)=0.3, & \mu_{B}^{-}(y z)=0.4, & \mu_{B}^{-}(z x)=0.3, \\
\mu_{B}^{+}(x y)=0.5, & \mu_{B}^{+}(y z)=0.6, & \mu_{B}^{+}(z x)=0.5 .
\end{array}
$$

Routine computations show that $G$ is both complete and totally regular interval-valued fuzzy graph, but $G$ is not regular since $\operatorname{deg}(x) \neq \operatorname{deg}(z) \neq \operatorname{deg}(y)$.

Theorem 12. Every complete interval-valued fuzzy graph is totally regular.

Theorem 13. Let $G=(A, B)$ be an interval-valued fuzzy graph of a graph $G^{*}$. Then, $A=\left[\mu_{A}^{-}, \mu_{A}^{+}\right]$is a constant function if and only if the following statements are equivalent:
(a) $G$ is a regular interval-valued fuzzy graph,
(b) $G$ is a totally regular interval-valued fuzzy graph.

Proof. Suppose that $A=\left[\mu_{A}^{-}, \mu_{A}^{+}\right]$is a constant function. Let $\mu_{A}^{-}(x)=c_{1}$ and $\mu_{A}^{+}(x)=c_{2}$ for all $x \in V$.

(a) $\Rightarrow$ (b): Assume that $G$ is an $n$-regular interval-valued fuzzy graph. Then, $\operatorname{deg}_{\mu^{-}}(x)=n_{1}$ and $\operatorname{deg}_{\mu^{+}}(x)=n_{2}$ for all $x \in V$. So,

$$
\begin{gathered}
\operatorname{deg}_{\mu^{-}}[x]=\operatorname{deg}_{\mu^{-}}(x)+\mu_{A}^{-}(x), \\
\operatorname{deg}_{\mu^{+}}[x]=\operatorname{deg}_{\mu^{+}}(x)+\mu_{A}^{+}(x), \quad \forall x \in V .
\end{gathered}
$$

Thus,

$$
\operatorname{deg}_{\mu^{-}}[x]=n_{1}+c_{1}, \quad \operatorname{deg}_{\mu^{+}}[x]=n_{2}+c_{2}, \quad \forall x \in V .
$$

Hence, $G$ is a totally regular interval-valued fuzzy graph.

(b) $\Rightarrow($ a): Suppose that $G$ is a totally regular intervalvalued fuzzy graph. Then,

$$
\operatorname{deg}_{\mu^{-}}[x]=k_{1}, \quad \operatorname{deg}_{\mu^{+}}[x]=k_{2}, \quad \forall x \in V,
$$

or

$$
\begin{aligned}
& \operatorname{deg}_{\mu^{-}}(x)+\mu_{A}^{-}(x)=k_{1}, \\
& \operatorname{deg}_{\mu^{+}}(x)+\mu_{A}^{+}(x)=k_{2}, \quad \forall x \in V,
\end{aligned}
$$

or

$$
\operatorname{deg}_{\mu^{-}}(x)+c_{1}=k_{1}, \quad \operatorname{deg}_{\mu^{+}}(x)+c_{2}=k_{2}, \quad \forall x \in V,
$$

or

$$
\operatorname{deg}_{\mu^{-}}(x)=k_{1}-c_{1}, \quad \operatorname{deg}_{\mu^{+}}(x)=k_{2}-c_{2}, \quad \forall x \in V
$$

Thus, $G$ is a regular interval-valued fuzzy graph. Hence, (a) and (b) are equivalent.

The converse part is obvious.

Theorem 14. Let $G$ be an interval-valued fuzzy graph where a crisp graph $G^{*}$ is an odd cycle. Then, $G$ is a regular intervalvalued fuzzy graph if and only if $B$ is a constant function.

Proof. If $B=\left[\mu_{B}^{-}, \mu_{B}^{+}\right]$is a constant function, say $\mu_{B}^{-}=c_{1}$ and $\mu_{B}^{+}=c_{2}$ for all $x y \in E$; then, $\operatorname{deg}_{\mu^{-}}(x)=2 c_{1}$ and $\operatorname{deg}_{\mu^{+}}(x)=$ $2 c_{2}$ for every $x \in V$. Hence $G$ is a regular interval-valued fuzzy graph.

Conversely, suppose that $G$ is a $\left(k_{1}, k_{2}\right)$-regular intervalvalued fuzzy graph. Let $e_{1}, e_{2}, \ldots, e_{2 n+1}$ be the edges of $G$ in that order. Let $\mu_{B}^{-}\left(e_{1}\right)=c_{1}, \mu_{B}^{-}\left(e_{2}\right)=k_{1}-c_{1}, \mu_{B}^{-}\left(e_{3}\right)=k_{1}-$ $\left(k_{1}-c_{1}\right)=c_{1}, \mu_{B}^{-}\left(e_{4}\right)=k_{1}-c_{1}$, and so on. Therefore,

$$
\mu_{B}^{-}\left(e_{i}\right)= \begin{cases}c_{1}, & \text { if } i \text { is odd, } \\ k_{1}-c_{1}, & \text { if } i \text { is even. }\end{cases}
$$

Thus, $\mu_{B}^{-}\left(e_{1}\right)=\mu_{B}^{-}\left(e_{2 n+1}\right)=c_{1}$. So, if $e_{1}$ and $e_{2 n+1}$ incident at a vertex $v_{1}$, then $\operatorname{deg}_{\mu^{-}}\left(v_{1}\right)=k_{1}, \operatorname{deg}_{\mu^{-}}\left(e_{1}\right)+\operatorname{deg}_{\mu^{-}}\left(e_{2 n+1}\right)=k_{1}$, $c_{1}+c_{1}=k_{1}, 2 c_{1}=k_{1}$, and $c_{1}=k_{1} / 2$. This shows that $\mu_{B}^{-}$is a regular function.

Similarly, let $\mu_{B}^{+}\left(e_{1}\right)=c_{2}, \mu_{B}^{+}\left(e_{2}\right)=k_{2}-c_{2}, \mu_{B}^{+}\left(e_{3}\right)=k_{2}-$ $\left(k_{2}-c_{2}\right)=c_{2}, \mu_{B}^{+}\left(e_{4}\right)=k_{2}-c_{2}$, and so on. Therefore,

$$
\mu_{B}^{+}\left(e_{i}\right)= \begin{cases}c_{2}, & \text { if } i \text { is odd } \\ k_{2}-c_{2}, & \text { if } i \text { is even. }\end{cases}
$$

Thus, $\mu_{B}^{+}\left(e_{2}\right)=\mu_{B}^{+}\left(e_{2 n+1}\right)=c_{2}$. So, if $e_{2}$ and $e_{2 n}$ incident at a vertex $v_{2}$, then $\operatorname{deg}_{\mu^{+}}\left(v_{2}\right)=k_{2}, \operatorname{deg}_{\mu^{+}}\left(e_{2}\right)+\operatorname{deg}_{\mu^{+}}\left(e_{2 n+1}\right)=$ $k_{2}, c_{2}+c_{2}=k_{2}, 2 c_{2}=k_{2}$, and $c_{2}=k_{2} / 2$. This shows that $\mu_{B}^{+}$is a constant function. Hence, $B=\left[\mu_{B}^{-}, \mu_{B}^{+}\right]$is a constant function.

We state the following characterization without its proof.

Theorem 15. Let $G$ be an interval-valued fuzzy graph where a crisp graph $G^{*}$ is an even cycle. Then, $G$ is a regular intervalvalued fuzzy graph if and only if either $B=\left[\mu_{B}^{-}, \mu_{B}^{+}\right]$is a constant function or alternate edges have the same membership values.

Definition 16. The density of an interval-valued fuzzy graphs $G$ is $D(G)=\left(D^{-}(G), D^{+}(G)\right)$, where $D^{-}(G)=$ $\left(2 \sum_{x, y \in V}\left(\mu_{B}^{-}(x y)\right)\right) /\left(\sum_{x, y \in V}\left(\mu_{A}^{-}(x) \wedge \mu_{A}^{-}(y)\right)\right)$ for $x, y \in V$ and $D^{+}(G)=\left(2 \sum_{x, y \in V}\left(\mu_{B}^{+}(x y)\right)\right) /\left(\sum_{x, y \in V}\left(\mu_{A}^{+}(x) \wedge \mu_{A}^{+}(y)\right)\right)$ for $x, y \in V$. An interval-valued fuzzy graph $G$ is balanced if $D(H) \leq D(G)$; that is, $D^{-}(H) \leq D^{-}(G), D^{+}(H) \leq D^{+}(G)$ for all subgraphs $H$ of $G$. An interval-valued fuzzy graph $G$ is strictly balanced if for every $x, y \in V, D(H)=D(G)$ for all nonempty subgraphs. 
Example 17. Consider the regular interval-valued fuzzy graph $G$ which is given in Example 7. Routine calculations show that $D^{-}(G)=0.67$ and $D^{+}(G)=1.2$. Thus, $D(G)=(0.67,1.2)$. Consider that $H_{1}=\{a, b, c\}, H_{2}=\{a, c\}, H_{3}=\{a, d\}$, and $H_{4}=\{b, c\}$ are a nonempty subgraphs of $G$. Then, $D\left(H_{1}\right)=$ $(0.67,1.2), D\left(H_{2}\right)=(0,0), D\left(H_{3}\right)=(0.67,1.6)$, and $D\left(H_{4}\right)=$ $(0.67,1.6)$. It is easy to see that regular interval-valued fuzzy graph is not balanced.

Remark 18. Every regular interval-valued fuzzy graph may not be balanced.

Example 19. Consider the regular interval-valued fuzzy graph $G$ which is given in Example 11. Routine calculations show that $D^{-}(G)=2$ and $D^{+}(G)=2$. Thus, $D(G)=(2,2)$. Consider $H_{1}=\{x, y\}, H_{2}=\{x, z\}, H_{3}=\{y, z\}$ be a nonempty subgraphs of $G$. Then, $D\left(H_{1}\right)=(2,2), D\left(H_{2}\right)=(2,2)$, and $D\left(H_{3}\right)=(2,2)$. It is easy to see that complete interval-valued fuzzy graph is balanced. $G$ is also strictly balanced.

Proposition 20. Any complete interval-valued fuzzy graph is balanced.

Proposition 21. Let $G$ be a self-complementary intervalvalued fuzzy graph. Then, $D(G)=(1,1)$.

Proposition 22. Let $G_{1}$ and $G_{2}$ be two balanced intervalvalued fuzzy graphs. Then, $G_{1} \times G_{2}$ is balanced if and only if $D\left(G_{1}\right)=D\left(G_{2}\right)=D\left(G_{1} \times G_{2}\right)$.

Theorem 23. Let $G$ be a strictly balanced interval-valued fuzzy graph, and let $\bar{G}$ be its complement; then $D(G)+D(\bar{G})=(2,2)$.

Proof. Let $G$ be a strictly balanced interval-valued fuzzy graph and $\bar{G}$ its complement. Let $H$ be a nonempty subgraph of $G$. Since $G$ is strictly balanced, $D(G)=D(H)$ for every $H \subseteq G$ and $x, y \in V$. In $\bar{G}$,

$$
\begin{aligned}
& \overline{\mu_{B}^{-}(x y)}=\mu_{A}^{-}(x) \wedge \mu_{A}^{-}(y)-\mu_{B}^{-}(x y), \\
& \overline{\mu_{B}^{+}(x y)}=\mu_{A}^{+}(x) \wedge \mu_{A}^{+}(y)-\mu_{B}^{+}(x y),
\end{aligned}
$$

for every $x, y \in V$. Dividing (16) by $\mu_{A}^{-}(x) \wedge \mu_{A}^{-}(y)$, we get

$$
\frac{\overline{\mu_{B}^{-}(x y)}}{\mu_{A}^{-}(x) \wedge \mu_{A}^{-}(y)}=1-\frac{\mu_{B}^{-}(x y)}{\mu_{A}^{-}(x) \wedge \mu_{A}^{-}(y)}, \quad \text { for every } x, y \in V
$$

and dividing (17) by $\mu_{A}^{+}(x) \wedge \mu_{A}^{+}(y)$, we get

$$
\frac{\overline{\mu_{B}^{+}(x y)}}{\mu_{A}^{+}(x) \wedge \mu_{A}^{+}(y)}=1-\frac{\mu_{B}^{+}(x y)}{\mu_{A}^{+}(x) \wedge \mu_{A}^{+}(y)}, \quad \text { for every } x, y \in V \text {. }
$$

Then,

$$
\begin{aligned}
& \sum_{x, y \in V} \frac{\overline{\mu_{B}^{-}(x y)}}{\mu_{A}^{-}(x) \wedge \mu_{A}^{-}(y)} \\
& \quad=1-\sum_{x, y \in V} \frac{\mu_{B}^{-}(x y)}{\mu_{A}^{-}(x) \wedge \mu_{A}^{-}(y)}, \quad \text { for every } x, y \in V, \\
& \sum_{x, y \in V} \frac{\overline{\mu_{B}^{+}(x y)}}{\mu_{A}^{+}(x) \wedge \mu_{A}^{+}(y)} \\
& \quad=1-\sum_{x, y \in V} \frac{\mu_{B}^{+}(x y)}{\mu_{A}^{+}(x) \wedge \mu_{A}^{+}(y)}, \quad \text { for every } x, y \in V .
\end{aligned}
$$

Multiplying both sides the above equations by 2 ,

$$
\begin{aligned}
& 2 \sum_{x, y \in V} \frac{\overline{\overline{\mu_{B}^{-}(x y)}}}{\overline{\mu_{A}^{-}(x)} \wedge \overline{\mu_{A}^{-}(y)}} \\
& \quad=2-2 \sum_{x, y \in V} \frac{\mu_{B}^{-}(x y)}{\mu_{A}^{-}(x) \wedge \mu_{A}^{-}(y)}, \quad \text { for every } x, y \in V, \\
& 2 \sum_{x, y \in V} \frac{\overline{\mu_{B}^{+}(x y)}}{\overline{\mu_{A}^{+}(x)} \wedge \overline{\mu_{A}^{+}(y)}} \\
& \quad=2-2 \sum_{x, y \in V} \frac{\mu_{B}^{+}(x y)}{\mu_{A}^{+}(x) \wedge \mu_{A}^{+}(y)}, \quad \text { for every } x, y \in V .
\end{aligned}
$$

Thus, $D^{-}(\bar{G})=2-D^{-}(G)$ and $D^{+}(\bar{G})=2-D^{+}(G)$.

Now,

$$
\begin{aligned}
D(G)+D(\bar{G}) & =\left(D^{-}(G), D^{+}(G)\right)+\left(D^{-}(\bar{G}), D^{+}(\bar{G})\right) \\
& =\left(D^{-}(G)+D^{-}(\bar{G})\right),\left(D^{+}(G)+D^{+}(\bar{G})\right) \\
& =(2,2) .
\end{aligned}
$$

This completes the proof.

Corollary 24. The complement of strictly balanced intervalvalued fuzzy graph is strictly balanced.

Theorem 25. Let $G_{1}$ and $G_{2}$ be isomorphic interval-valued fuzzy graphs. If $G_{2}$ is balanced, then $G_{1}$ is balanced.

\section{Irregularity in Interval-Valued Fuzzy Graphs}

Definition 26. Let $G$ be an interval-valued fuzzy graph on $G^{*}$. If there is a vertex which is adjacent to vertices with distinct neighbourhood degrees, then $G$ is called an irregular intervalvalued fuzzy graph. That is, $\operatorname{deg}(x) \neq n$ for all $x \in V$. 


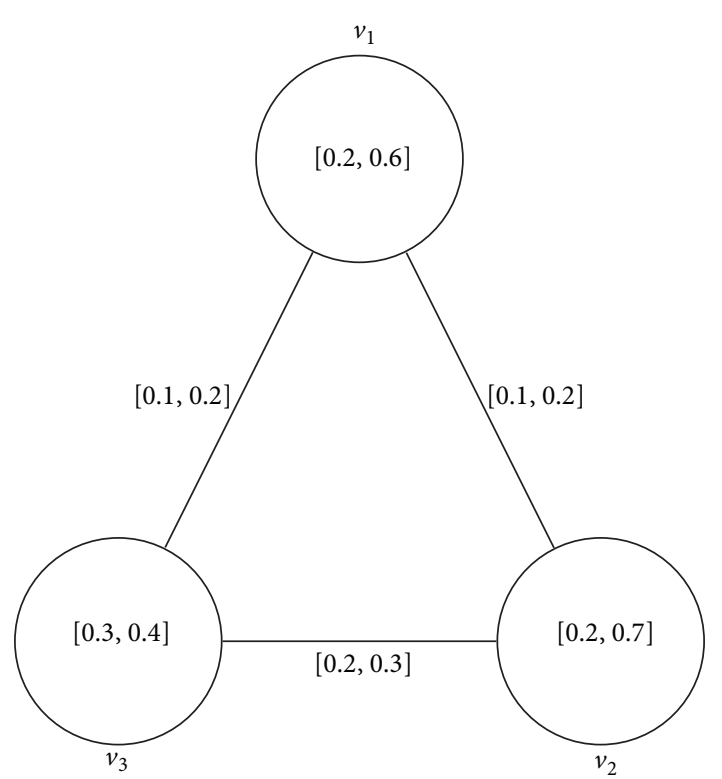

FIGURE 2: Irregular interval-valued fuzzy graph.

Example 27. Consider a graph $G^{*}$ such that

$$
V=\left\{v_{1}, v_{2}, v_{3}\right\}, \quad E=\left\{v_{1} v_{2}, v_{2} v_{3}, v_{1} v_{3}\right\} .
$$

Let $A$ be an interval-valued fuzzy subset of $V$, and let $B$ be an interval-valued fuzzy subset of $E \subseteq V \times V$ defined by

$$
\begin{gathered}
{\left[\begin{array}{c|ccc} 
& v_{1} & v_{2} & v_{3} \\
\hline \mu_{A}^{-} & 0.2 & 0.2 & 0.3 \\
\mu_{A}^{+} & 0.6 & 0.7 & 0.4
\end{array}\right],} \\
{\left[\begin{array}{c|ccc} 
& v_{1} v_{2} & v_{1} v_{3} & v_{2} v_{3} \\
\hline \mu_{B}^{-} & 0.1 & 0.1 & 0.2 \\
\mu_{B}^{+} & 0.2 & 0.2 & 0.3
\end{array}\right] .}
\end{gathered}
$$

By routine computations, we have $\operatorname{deg}\left(v_{1}\right)=[0.5,1.1]$, $\operatorname{deg}\left(v_{2}\right)=[0.5,1.0]$, and $\operatorname{deg}\left(v_{3}\right)=[0.4,1.3]$. It is clear that $G$ as shown in Figure 2 is an irregular interval-valued fuzzy graph.

Definition 28. Let $G$ be an interval-valued fuzzy graph. If there is a vertex which is adjacent to vertices with distinct closed neighbourhood degrees, then $G$ is called a totally irregular interval-valued fuzzy graph.

Example 29. Consider an interval-valued fuzzy graph $G$ such that

$$
\begin{aligned}
& V=\left\{v_{1}, v_{2}, v_{3}, v_{4}, v_{5}\right\}, \\
& E=\left\{v_{1} v_{2}, v_{2} v_{3}, v_{2} v_{4}, v_{3} v_{1}, v_{3} v_{4}, v_{4} v_{1}, v_{4} v_{5}\right\} .
\end{aligned}
$$

By routine computations, we have $\operatorname{deg}\left[v_{1}\right]=[1.4,2.4]$, $\operatorname{deg}\left[v_{2}\right]=[1.4,2.4], \operatorname{deg}\left[v_{3}\right]=[1.4,2.4], \operatorname{deg}\left[v_{4}\right]=[1.6,2.6]$, and $\operatorname{deg}\left[v_{5}\right]=[0.6,0.8]$. It is clear from calculations that $G$ as

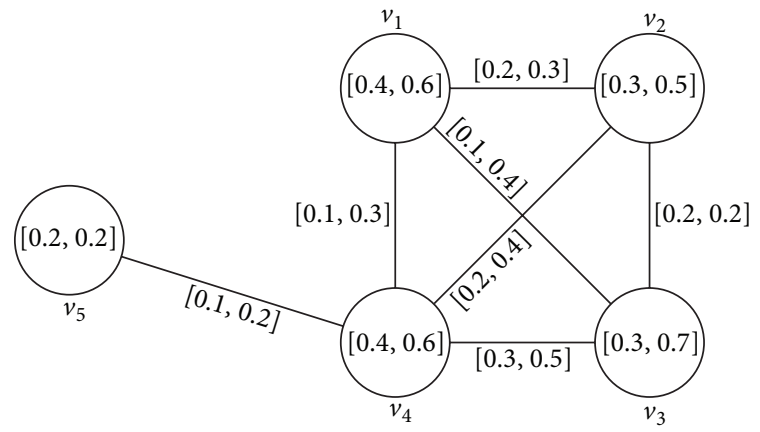

FIGURE 3: $G$ is totally irregular.

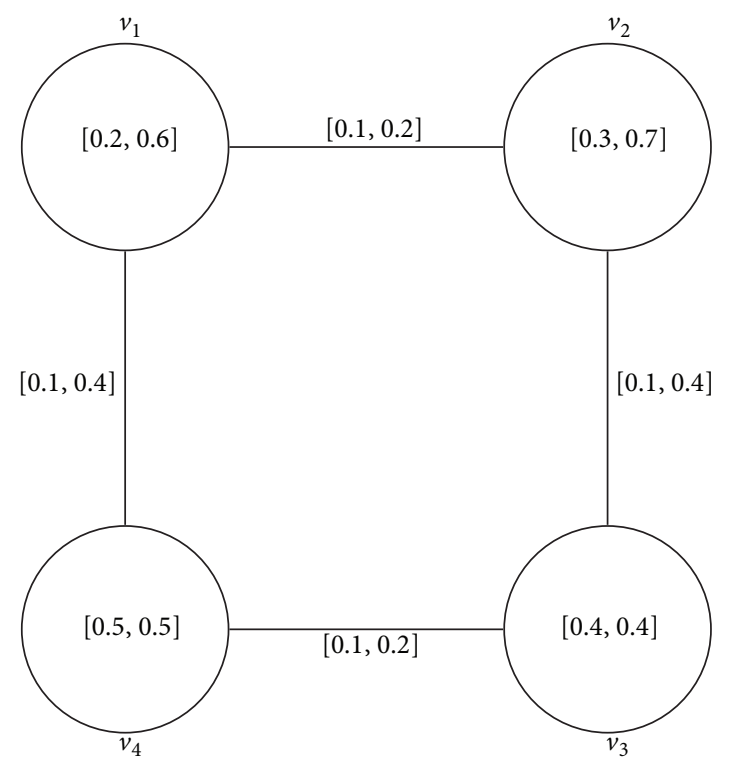

FIGURE 4: $G$ is neighbourly irregular.

shown in Figure 3 is a totally irregular interval-valued fuzzy graph.

Definition 30. A connected interval-valued fuzzy graph $G$ is said to be neighbourly irregular if every two adjacent vertices of $G$ have distinct open neighbourhood degree.

Example 31. Consider an interval-valued fuzzy graph $G$ such that

$$
\begin{aligned}
& V=\left\{v_{1}, v_{2}, v_{3}, v_{4}\right\} \\
& E=\left\{v_{1} v_{2}, v_{2} v_{3}, v_{3} v_{4}, v_{4} v_{1}\right\} .
\end{aligned}
$$

By routine computations, we have $\operatorname{deg}\left(v_{1}\right)=[0.8,1.2]$, $\operatorname{deg}\left(v_{2}\right)=[0.6,1.0], \operatorname{deg}\left(v_{3}\right)=[0.8,1.2]$, and $\operatorname{deg}\left(v_{4}\right)=$ $[0.6,1.0]$. Hence, $G$ as shown in Figure 4 is neighbourly irregular.

Definition 32. A connected interval-valued fuzzy graph $G$ is said to be neighbourly totally irregular if every two adjacent vertices of $G$ have distinct closed neighbourhood degree. 


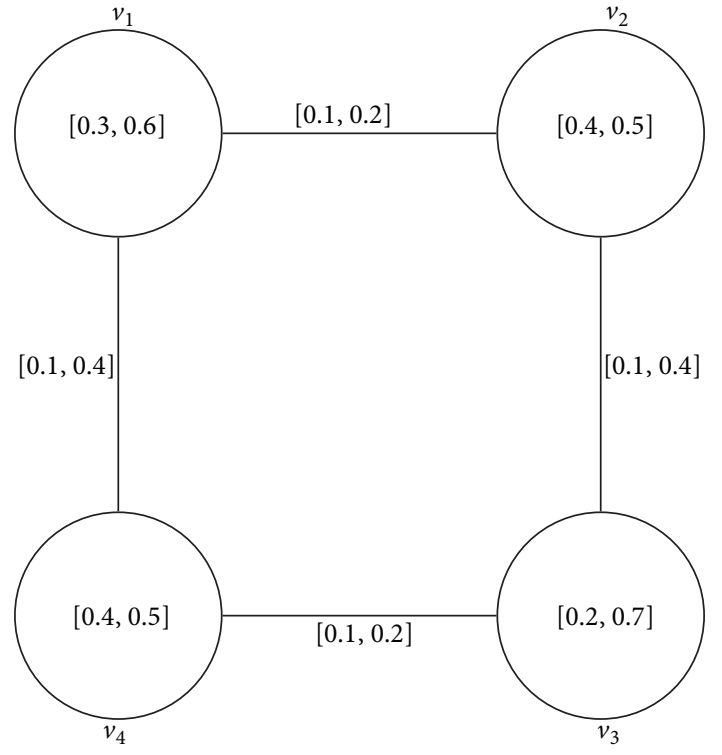

FIGURE 5: $G$ is neighbourly totally irregular.

Example 33. Consider an interval-valued fuzzy graph $G$ such that

$$
\begin{aligned}
& V=\left\{v_{1}, v_{2}, v_{3}, v_{4}\right\}, \\
& E=\left\{v_{1} v_{2}, v_{2} v_{3}, v_{3} v_{4}, v_{4} v_{1}\right\} .
\end{aligned}
$$

By routine computations, we have $\operatorname{deg}\left[v_{1}\right]=[1.1,1.6]$, $\operatorname{deg}\left[v_{2}\right]=[0.9,1.8], \operatorname{deg}\left[v_{3}\right]=[1.0,1.7]$, and $\operatorname{deg}\left[v_{4}\right]=$ $[0.9,1.8]$. Hence, $G$ as shown in Figure 5 is neighbourly totally irregular.

Definition 34. Let $G$ be a connected interval-valued fuzzy graph. $G$ is called highly irregular if every vertex of $G$ is adjacent to vertices with distinct neighbourhood degrees.

Example 35. Consider an interval-valued fuzzy graph $G$ such that

$$
\begin{aligned}
& V=\left\{v_{1}, v_{2}, v_{3}, v_{4}, v_{5}, v_{6}\right\}, \\
& E=\left\{v_{1} v_{2}, v_{2} v_{3}, v_{2} v_{6}, v_{3} v_{4}, v_{3} v_{5}, v_{4} v_{5}, v_{5} v_{1}\right\} .
\end{aligned}
$$

By routine computations, we have $\operatorname{deg}\left(v_{1}\right)=[0.4,0.8]$, $\operatorname{deg}\left(v_{2}\right)=[0.6,1.7], \operatorname{deg}\left(v_{3}\right)=[0.9,1.3], \operatorname{deg}\left(v_{4}\right)=[0.6,1.1]$, $\operatorname{deg}\left(v_{5}\right)=[1.0,1.8]$, and $\operatorname{deg}\left(v_{6}\right)=[0.1,0.4]$. Clearly, $G$ as shown in Figure 6 is highly irregular.

Example 36. Consider an interval-valued fuzzy graph $G$ such that

$$
\begin{aligned}
& V=\left\{v_{1}, v_{2}, v_{3}, v_{4}\right\}, \\
& E=\left\{v_{1} v_{2}, v_{2} v_{3}, v_{3} v_{4}, v_{4} v_{1}\right\} .
\end{aligned}
$$

By routine computations, we have $\operatorname{deg}\left(v_{1}\right)=[0.6,1.0]$, $\operatorname{deg}\left(v_{2}\right)=[0.8,0.9], \operatorname{deg}\left(v_{3}\right)=[0.6,1.0]$, and $\operatorname{deg}\left(v_{4}\right)=$

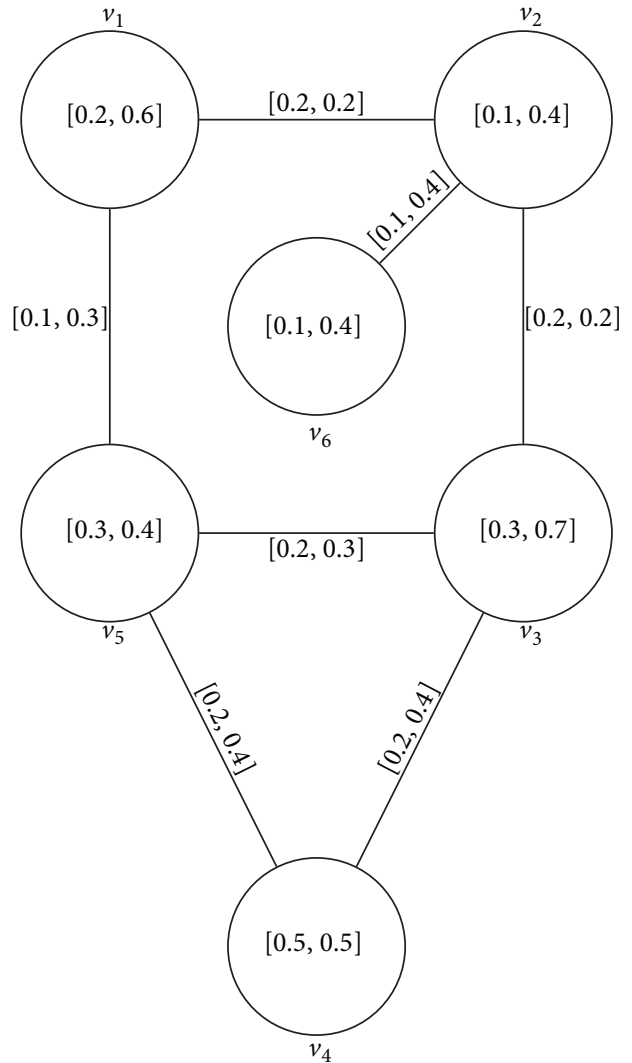

FIGURE 6: $G$ is highly irregular.

$[0.8,0.9]$. We see that every two adjacent vertices have distinct open neighbourhood degree. But the vertex $v_{2}$ adjacent to the vertices $v_{1}$ and $v_{3}$ has the same neighbourhood degree, that is, $\operatorname{deg}\left(v_{1}\right)=\operatorname{deg}\left(v_{3}\right)$. Hence, $G$ as shown in Figure 7 is neighbourly irregular but not highly irregular.

Remark 37. A neighbourly irregular interval-valued fuzzy graph may not be highly irregular.

Theorem 38. An interval-valued fuzzy graph $G$ is highly irregular and neighbourly irregular interval-valued fuzzy graph if and only if the neighbourhood degrees of all the vertices of $G$ are distinct.

Proof. Let $G$ be an interval-valued fuzzy graph with $n$ vertices $v_{1}, v_{2}, \ldots, v_{n}$. Assume that $G$ is highly irregular and neighbourly irregular.

Claim 1. The neighbourhood degrees of all vertices of $G$ are distinct. Let $\operatorname{deg}\left(v_{i}\right)=\left[k_{i}, l_{i}\right], i=1,2, \ldots, n$. Let the adjacent vertices of $v_{1}$ be $v_{2}, v_{3}, \ldots, v_{n}$ with neighbourhood degrees $\left[k_{2}, l_{2}\right],\left[k_{3}, l_{3}\right], \ldots,\left[k_{n}, l_{n}\right]$, respectively. Then, $k_{2} \neq k_{3} \neq \cdots \neq k_{n}$ and $l_{2} \neq l_{3} \neq \cdots \neq l_{n}$, since $G$ is highly irregular. Also $k_{1} \neq k_{2} \neq k_{3} \neq \cdots \neq k_{n}$ and $l_{1} \neq l_{2} \neq l_{3} \neq \cdots \neq l_{n}$, since $G$ is neighbourly irregular. Hence, the neighbourhood degree of all the vertices of $G$ is distinct. 


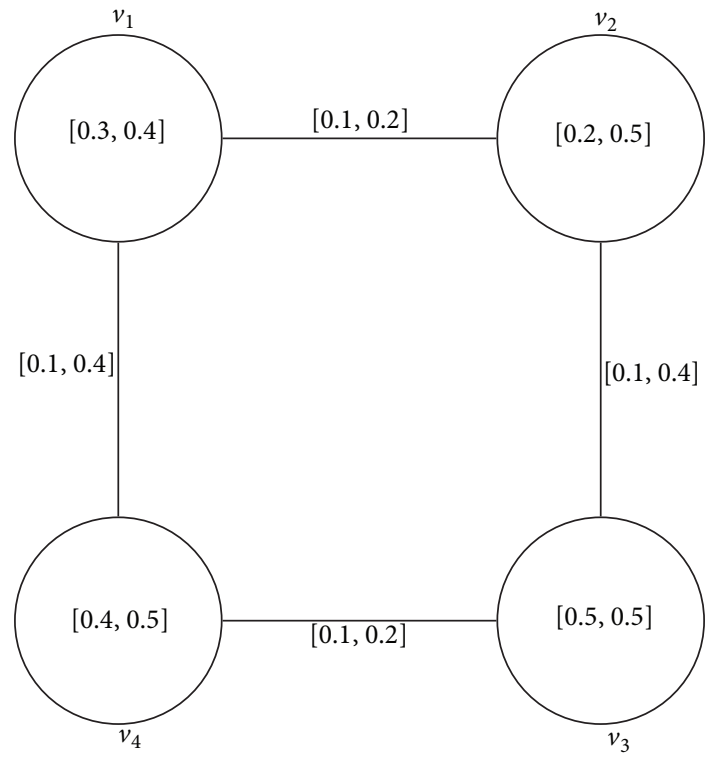

FIGURE 7: $G$ is neighbourly irregular but not highly irregular.

Conversely, assume that the neighbourhood degrees of all the vertices of $G$ are distinct.

Claim 2. $G$ is highly irregular and neighbourly irregular interval-valued fuzzy graph.

Let $\operatorname{deg}\left(v_{i}\right)=\left[k_{i}, l_{i}\right], i=1,2, \ldots, n$. Given that $k_{1} \neq k_{2} \neq k_{3} \neq \cdots \neq k_{n}$ and $l_{1} \neq l_{2} \neq l_{3} \neq \cdots \neq l_{n}$, which implies that every two adjacent vertices have distinct neighbourhood degrees and to every vertex, the adjacent vertices have distinct neighbourhood degrees.

Theorem 39. An interval-valued fuzzy graph $G$ of $G^{*}$, where $G^{*}$ is a cycle with 3 vertices that is neighbourly irregular and highly irregular if and only if the lower and upper membership values of the vertices between every pair of vertices are all distinct.

Proof. Assume that lower and upper membership values of the vertices are all distinct.

Claim 1. G is neighbourly irregular and highly irregular interval-valued fuzzy graph.

Let $v_{i}, v_{j}, v_{k} \in V$. Given that $\mu_{A}^{-}\left(v_{i}\right) \neq \mu_{A}^{-}\left(v_{j}\right) \neq$ $\mu_{A}^{-}\left(v_{k}\right)$ and $\mu_{A}^{+}\left(v_{i}\right) \neq \mu_{A}^{+}\left(v_{j}\right) \neq \mu_{A}^{+}\left(v_{k}\right)$, which implies that $\sum_{x \in N(x)} \mu_{A}^{-}\left(v_{i}\right) \neq \sum_{x \in N(x)} \mu_{A}^{-}\left(v_{j}\right) \neq \sum_{x \in N(x)} \mu_{A}^{-}\left(v_{k}\right) \quad$ and $\sum_{x \in N(x)} \mu_{A}^{+}\left(v_{i}\right) \neq \sum_{x \in N(x)} \mu_{A}^{+}\left(v_{j}\right) \neq \sum_{x \in N(x)} \mu_{A}^{+}\left(v_{k}\right)$. That is, $\operatorname{deg}\left(v_{i}\right) \neq \operatorname{deg}\left(v_{j}\right) \neq \operatorname{deg}\left(v_{k}\right)$. Hence, $G$ is neighbourly irregular and highly irregular.

Conversely, assume that $G$ is neighbourly irregular and highly irregular.

Claim 2. Lower and upper membership values of the vertices are all distinct.

Let $\operatorname{deg}\left(v_{i}\right)=\left[k_{i}, l_{i}\right], i=1,2, \ldots, n$. Suppose that lower and upper membership value of any two vertices are the

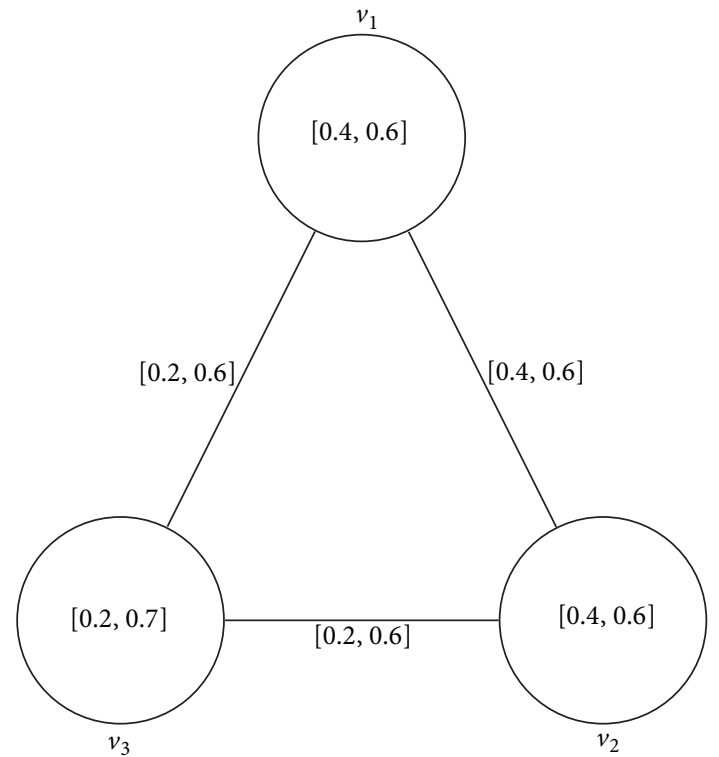

FIGURE 8: $G$ is not neighbourly irregular, but it is complete.

same. Let $v_{1}, v_{2} \in V$. Let $\mu_{A}^{-}\left(v_{1}\right)=\mu_{A}^{-}\left(v_{2}\right)$ and $\mu_{A}^{+}\left(v_{1}\right)=$ $\mu_{A}^{+}\left(v_{2}\right)$. Then, $\operatorname{deg}\left(v_{1}\right)=\operatorname{deg}\left(v_{2}\right)$, since $G^{*}$ is cycle, which is a contradiction to the fact that $G$ is neighbourly irregular and highly irregular interval-valued fuzzy graph. Hence, lower membership and upper membership value of the vertices are all distinct.

Remark 40. A complete interval-valued fuzzy graph may not be neighbourly irregular.

Example 41. Consider an interval-valued fuzzy graph $G$ such that

$$
V=\left\{v_{1}, v_{2}, v_{3}\right\}, \quad E=\left\{v_{1} v_{2}, v_{2} v_{3}, v_{1} v_{3}\right\}
$$

By routine computations, we have $\operatorname{deg}\left(v_{1}\right)=[0.6,1.3]$, $\operatorname{deg}\left(v_{2}\right)=[0.6,1.3]$, and $\operatorname{deg}\left(v_{3}\right)=[0.8,1.2]$. We see that neighbourhood degree of $v_{1}$ and $v_{2}$ is not distinct. Hence, $G$ as shown in Figure 8 is not neighbourly irregular, but it is complete.

Remark 42. A neighbourly total irregular interval-valued fuzzy graph may not be neighbourly irregular.

Example 43. Consider an interval-valued fuzzy graph $G$ such that

$$
V=\left\{v_{1}, v_{2}, v_{3}, v_{4}\right\}, \quad E=\left\{v_{1} v_{2}, v_{2} v_{3}, v_{3} v_{4}, v_{4} v_{1}\right\} .
$$

By routine computations, we have $\operatorname{deg}\left(v_{1}\right)=[0.7,0.9]$, $\operatorname{deg}\left(v_{2}\right)=[0.8,1.1], \operatorname{deg}\left(v_{3}\right)=[0.7,0.9], \operatorname{deg}\left(v_{4}\right)=[0.8,1.1]$, $\operatorname{deg}\left[v_{1}\right]=[1.1,1.5], \operatorname{deg}\left[v_{2}\right]=[1.1,1.5], \operatorname{deg}\left[v_{3}\right]=[1.1,1.4]$, and $\operatorname{deg}\left[v_{4}\right]=[1.2,1.6]$. We see that $\operatorname{deg}\left[v_{1}\right]=\operatorname{deg}\left[v_{2}\right]$. Hence, $G$ as shown in Figure 9 is neighbourly irregular but not a neighbourly total irregular. 


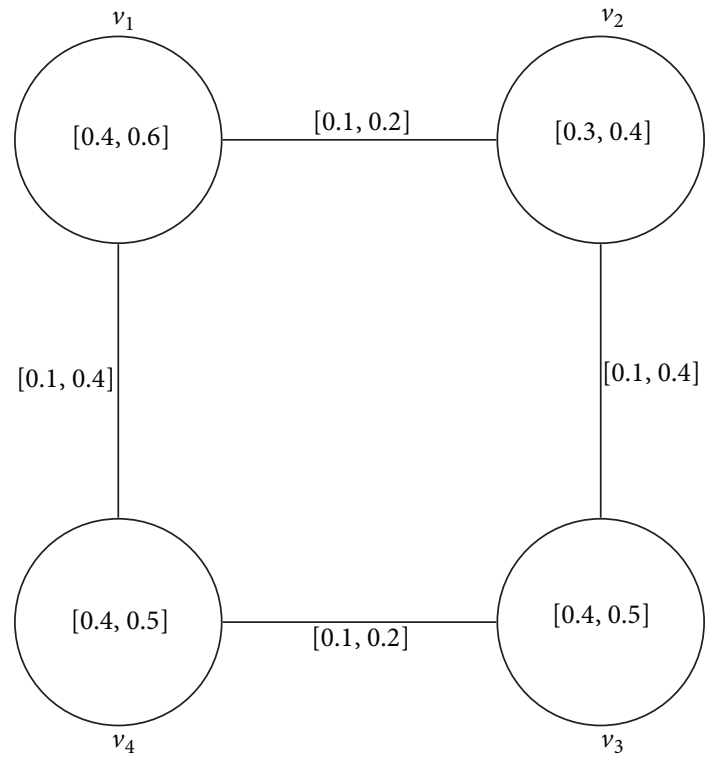

FIGURE 9: $G$ is neighbourly irregular but not neighbourly total irregular.

Proposition 44. If an interval-valued fuzzy graph $G$ is neighbourly irregular and $\left[\mu_{A}^{-}, \mu_{A}^{+}\right]$is a constant function, then it is neighbourly totally irregular.

Proof. Assume that $G$ is a neighbourly irregular intervalvalued fuzzy graph. Then, the open neighbourhood degrees of every two adjacent vertices are distinct. Let $v_{i}, v_{j} \in V$ be adjacent vertices with distinct open neighbourhood degrees $\left[k_{1}, l_{1}\right]$ and $\left[k_{2}, l_{2}\right]$, where $k_{1} \neq k_{2}, l_{1} \neq l_{2}$. Let us assume that $\left(\mu_{1}\left(v_{i}\right), v_{1}\left(v_{i}\right)\right)=\left(\mu_{1}\left(v_{j}\right), v_{1}\left(v_{j}\right)\right)=\left[c_{1}, c_{2}\right]$, where $c_{1}, c_{2}$ are constant and $c_{1}, c_{2} \in[0,1]$. Therefore, $\operatorname{deg}_{\mu^{-}}\left[v_{i}\right]=\operatorname{deg}_{\mu^{-}}\left(v_{i}\right)+$ $\mu_{1}\left(v_{i}\right)=k_{1}+c_{1}, \operatorname{deg}_{\mu^{+}}\left[v_{i}\right]=\operatorname{deg}_{\mu^{+}}\left(v_{i}\right)+v_{1}\left(v_{i}\right)=l_{1}+$ $c_{2} \operatorname{deg}_{\mu^{-}}\left[v_{j}\right]=\operatorname{deg}_{\mu^{-}}\left(v_{j}\right)+\mu_{1}\left(v_{j}\right)=k_{2}+c_{1}$, and $\operatorname{deg}_{\mu^{+}}\left[v_{j}\right]=$ $\operatorname{deg}_{\mu^{+}}\left(v_{j}\right)+v_{1}\left(v_{j}\right)=l_{2}+c_{2}$.

Claim. Consider that $\operatorname{deg}_{\mu^{-}}\left[v_{i}\right] \neq \operatorname{deg}_{\mu^{-}}\left[v_{j}\right]$ and $\operatorname{deg}_{\mu^{+}}\left[v_{i}\right] \neq$ $\operatorname{deg}_{\mu^{+}}\left[v_{j}\right]$. Suppose that, $\operatorname{deg}_{\mu^{-}}\left[v_{i}\right]=\operatorname{deg}_{\mu^{-}}\left[v_{j}\right]$ and $\operatorname{deg}_{\mu^{+}}\left[v_{i}\right]=\operatorname{deg}_{\mu^{+}}\left[v_{j}\right]$. Consider that

$$
\begin{gathered}
\operatorname{deg}_{\mu^{-}}\left[v_{i}\right]=\operatorname{deg}_{\mu^{-}}\left[v_{j}\right], \\
k_{1}+c_{1}=k_{2}+c_{1}, \\
k_{1}-k_{2}=c_{1}-c_{1}=0,
\end{gathered}
$$

$k_{1}=k_{2}$, which is a contradiction to $k_{1} \neq k_{2}$.

Therefore, $\operatorname{deg}_{\mu^{-}}\left[v_{i}\right] \neq \operatorname{deg}_{\mu^{-}}\left[v_{j}\right]$. Similarly, we consider that

$$
\begin{gathered}
\operatorname{deg}_{\mu^{+}}\left[v_{i}\right]=\operatorname{deg}_{\mu^{+}}\left[v_{j}\right], \\
l_{1}+c_{2}=l_{2}+c_{2}, \\
l_{1}-l_{2}=c_{2}-c_{2}=0,
\end{gathered}
$$

$l_{1}=l_{2}$, which is a contradiction to $l_{1} \neq l_{2}$.
Therefore, $\operatorname{deg}_{\mu^{+}}\left[v_{i}\right] \neq \operatorname{deg}_{\mu^{+}}\left[v_{j}\right]$. Hence, $G$ is a neighbourly totally irregular interval-valued fuzzy graph.

Theorem 45. If an interval-valued fuzzy graph $G$ is neighbourly totally irregular and $\left[\mu_{A}^{-}, \mu_{A}^{+}\right]$is a constant function, then it is a neighbourly irregular interval-valued fuzzy graph.

Proof. Assume that $G$ is a neighbourly total irregular intervalvalued fuzzy graph. Then, the closed neighbourhood degree of every two adjacent vertices is distinct. Let $v_{i}, v_{j} \in V$ and $\operatorname{deg}\left[v_{i}\right]=\left[k_{1}, l_{1}\right], \operatorname{deg}\left[v_{j}\right]=\left[k_{2}, l_{2}\right]$, where $k_{1} \neq k_{2}$ and $l_{1} \neq l_{2}$. Assume that $\left(\mu_{1}\left(v_{i}\right), v_{1}\left(v_{i}\right)\right)=\left[c_{1}, c_{2}\right]$ and $\left(\mu_{1}\left(v_{j}\right), v_{1}\left(v_{j}\right)\right)=\left[c_{1}, c_{2}\right]$, where $c_{1}, c_{2} \in[0,1]$ are constant and $\operatorname{deg}\left[v_{i}\right] \neq \operatorname{deg}\left[v_{j}\right]$.

Claim. Consider that $\operatorname{deg}\left(v_{i}\right) \neq \operatorname{deg}\left(v_{j}\right)$.

Given that $\operatorname{deg}\left[v_{i}\right] \neq \operatorname{deg}\left[v_{j}\right]$ which implies $\operatorname{deg}_{\mu^{-}}\left[v_{i}\right] \neq$ $\operatorname{deg}_{\mu^{-}}\left[v_{j}\right]$ and $\operatorname{deg}_{\mu^{+}}\left[v_{i}\right] \neq \operatorname{deg}_{\mu^{+}}\left[v_{j}\right]$, now, we consider that

$$
\begin{aligned}
\operatorname{deg}_{\mu^{-}}\left[v_{i}\right] & \neq \operatorname{deg}_{\mu^{-}}\left[v_{j}\right], \\
k_{1}+c_{1} & \neq k_{2}+c_{1}, \\
k_{1} & \neq k_{2} .
\end{aligned}
$$

We now consider that

$$
\begin{aligned}
\operatorname{deg}_{\mu^{+}}\left[v_{i}\right] & \neq \operatorname{deg}_{\mu^{+}}\left[v_{j}\right], \\
l_{1}+c_{2} & \neq l_{2}+c_{2}, \\
l_{1} & \neq l_{2} .
\end{aligned}
$$

That is, the neighbourhood degrees of adjacent vertices of $G$ are distinct. Hence, neighbourhood degree of every pair of adjacent vertices is distinct in $G$.

Proposition 46. If an interval-valued fuzzy graph $G$ is neighbourly irregular and neighbourly totally irregular, then $\left[\mu_{A}^{-}, \mu_{A}^{+}\right]$ need not be a constant function.

Remark 47. If $G$ is a neighbourly irregular interval-valued fuzzy graph, then interval-valued subgraph $H=\left(A^{\prime}, B^{\prime}\right)$ of $G$ may not be neighbourly irregular.

Remark 48. If $G$ is a totally irregular interval-valued fuzzy graph, then interval-valued fuzzy subgraph $H=\left(A^{\prime}, B^{\prime}\right)$ of $G$ may not be totally irregular.

\section{Relationship between IFGs and IVFGs}

In 2003, Deschrijver and Kerre [31] established the relationships between some extensions of fuzzy sets. In this section, we present the relationship between extensions of fuzzy graphs. Shannon and Atanassov [32] introduced the notion of an intuitionistic fuzzy graph. Some operations on intuitionistic fuzzy graphs are discussed in [33].

Definition 49 (see [32]). By an intuitionistic fuzzy graph (IFG, for short) $G$ of a graph $G^{*}$, we mean a pair $G=(A, B)$, 


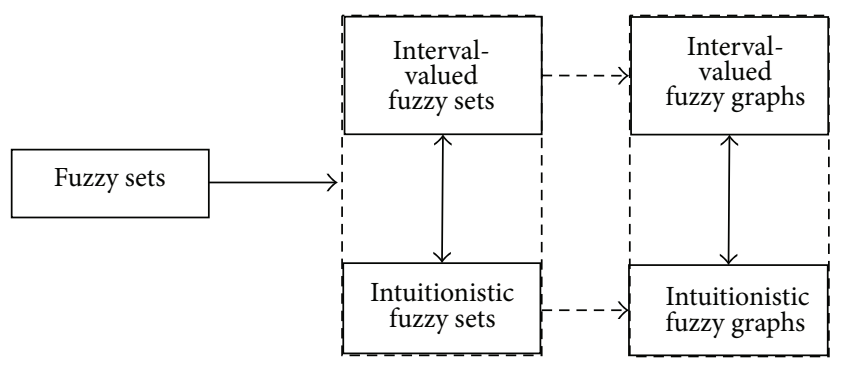

FIGURE 10: Links between models.

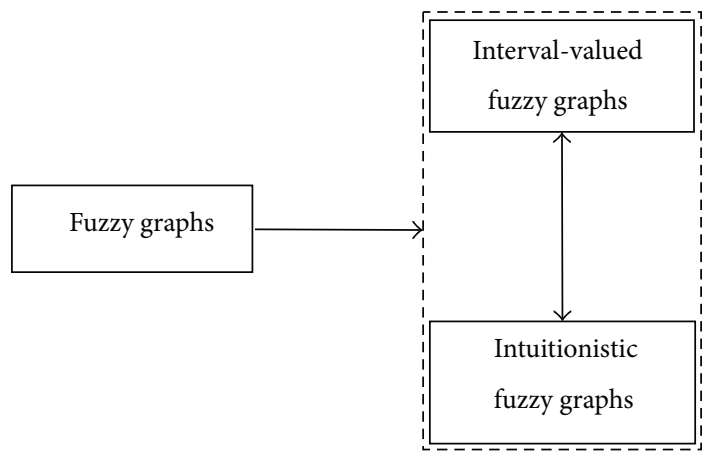

FIGURE 11: Link between IFGs and IVFGs.

where $A=\left(\mu_{A}, v_{A}\right)$ is an intuitionistic fuzzy set on $V$ and $B=\left(\mu_{B}, v_{B}\right)$ is an intuitionistic fuzzy relation on $E$ such that

$$
\begin{aligned}
& \mu_{B}(x y) \leq \min \left(\mu_{A}(x), \mu_{A}(y)\right), \\
& \nu_{B}(x y) \leq \max \left(v_{A}(x), v_{A}(y)\right),
\end{aligned}
$$

for all $x y \in E$. The class of all IFGs on $G^{*}$ will be denoted by $\mathscr{I} \mathscr{F} \mathscr{G}\left(G^{*}\right)$.

Theorem 50 (see [33]). If $G_{1}$ and $G_{2}$ are intuitionistic fuzzy graphs, then $G_{1} \cap G_{2}, G_{1} \cup G_{2}$, and $\overline{G_{1}}$ are intuitionistic fuzzy graphs.

Ju and Wang introduced the notion of interval-valued fuzzy graph (IVFG, for short) in [15]. Some operations on interval-valued fuzzy graphs are discussed in [18]. The class of all IVFGs on $G^{*}$ will be denoted by $\mathscr{I} \mathscr{V} \mathscr{F} \mathscr{G}\left(G^{*}\right)$.

Theorem 51 (see [19]). If $G_{1}$ and $G_{2}$ are interval-valued fuzzy graphs, then $G_{1} \cap G_{2}, G_{1} \cup G_{2}$, and $\overline{G_{1}}$ are interval-valued fuzzy graphs.

Lemma 52. $\left(\mathscr{I} \mathscr{V} \mathscr{F} \mathscr{G}\left(G^{*}\right), \cup, \cap\right)$ and $\left(\mathscr{I} \mathscr{F} \mathscr{G}\left(G^{*}\right), \cup, \cap\right)$ are complete lattices.

Theorem 53. The mapping

$$
\psi_{1}: \mathscr{I} \mathscr{V} \mathscr{F} \mathscr{G}\left(G^{*}\right) \longrightarrow \mathscr{I} \mathscr{F} \mathscr{G}\left(G^{*}\right)
$$

defined by

$$
\begin{aligned}
\psi_{1}(B)=( & \left\{\left(x, \mu_{A}^{-}(x), 1-\mu_{A}^{+}(x)\right) \mid x \in V\right\}, \\
& \left.\left\{\left(x y, \mu_{B}^{-}(x y), 1-\mu_{B}^{+}(x y)\right) \mid x y \in E\right\}\right),
\end{aligned}
$$

where

$$
\begin{aligned}
B=( & \left\{\left(x, \mu_{A}^{-}(x), \mu_{A}^{+}(x)\right) \mid x \in V\right\}, \\
& \left.\left\{\left(x y, \mu_{B}^{-}(x y), \mu_{B}^{+}(x y)\right) \mid x y \in E\right\}\right),
\end{aligned}
$$

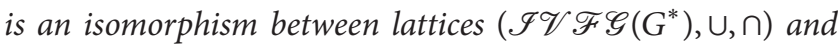
$\left(\mathscr{I} \mathscr{F} \mathscr{G}\left(G^{*}\right), \cup, \cap\right)$.

Remark 54. From a pure mathematical point of view, Theorem 53 shows that the two concepts intuitionistic fuzzy graphs and interval-valued fuzzy graphs are equivalent.

In Figures 10 and 11, we present the relationships that exist between different models. In these figures, a double arrow between two theories means that they are equivalent, a single arrow $X \rightarrow Y$ denotes that $Y$ is an extension of $X$. In Figure 10, a dash arrow $X \rightarrow \rightarrow Y$ denotes that model $Y$ is based on the previous model $X$.

\section{Conclusions}

Graph theory has several interesting applications in system analysis, operations research, computer applications, and economics. Since most of the time the aspects of graph problems are uncertain, it is nice to deal with these aspects via the methods of fuzzy systems. It is known that fuzzy graph theory has numerous applications in modern science and engineering, especially in the field of information theory, neural networks, expert systems, cluster analysis, medical diagnosis, traffic engineering, network routing, town planning, and control theory. Since interval-valued fuzzy set theory is an increasingly popular extension of fuzzy set theory where traditional $[0,1]$-valued membership degrees are replaced by intervals in $[0,1]$ that approximate the (unknown) membership degrees, specific types of intervalvalued fuzzy graphs have been introduced and investigated in this paper. The natural extension of this research work is the application of interval-valued fuzzy graphs in the area of soft computing including neural networks, expert systems, database theory, and geographical information systems.

\section{Acknowledgments}

The authors are thankful to the referees for their valuable comments. The authors are also thankful to Professor Syed Mansoor Sarwar and Dr. Faisal Aslam for their valuable suggestions.

\section{References}

[1] S. G. Shirinivas, S. Vetrivel, and N. M. Elango, "Applications of graph theory in computer science-an overview," International Journal of Engineering Science and Technology, vol. 2, no. 9, pp. 4610-4621, 2010. 
[2] N. Deo, Graph Theory with Applications to Engineering and Computer Science, Prentice Hall, Englewood Cliffs, NJ, USA, 1990.

[3] L. A. Zadeh, "The concept of a linguistic variable and its application to approximate reasoning-I," Information Sciences, vol. 8, pp. 199-249, 1975.

[4] K. T. Atanassov, "Intuitionistic fuzzy sets," Fuzzy Sets and Systems, vol. 20, no. 1, pp. 87-96, 1986.

[5] L. A. Zadeh, "Fuzzy sets," Information and Control, vol. 8, pp. 338-353, 1965.

[6] J. M. Mendel, Uncertain Rule-Based Fuzzy Logic Systems: Introduction and New Directions, Prentice-Hall, Upper Saddle River, NJ, USA, 2001.

[7] M. B. Gorzałczany, "A method of inference in approximate reasoning based on interval-valued fuzzy sets," Fuzzy Sets and Systems, vol. 21, no. 1, pp. 1-17, 1987.

[8] M. B. Gorzałczany, "An interval-valued fuzzy inference method-some basic properties," Fuzzy Sets and Systems, vol. 31, no. 2, pp. 243-251, 1989.

[9] M. K. Roy and R. Biswas, "I-V fuzzy relations and Sanchez's approach for medical diagnosis," Fuzzy Sets and Systems, vol. 47, no. 1, pp. 35-38, 1992.

[10] I. B. Türksen, "Interval valued fuzzy sets based on normal forms," Fuzzy Sets and Systems, vol. 20, no. 2, pp. 191-210, 1986.

[11] A. Kauffman, Introduction a la Theorie des Sous-emsembles Flous, vol. 1, Masson et Cie, 1973.

[12] A. Rosenfeld, "Fuzzy graphs," in Fuzzy Sets and Their Applications, L. A. Zadeh, K. S. Fu, and M. Shimura, Eds., pp. 77-95, Academic Press, New York, NY, USA, 1975.

[13] J. N. Mordeson and C.-S. Peng, "Operations on fuzzy graphs," Information Sciences, vol. 79, no. 3-4, pp. 159-170, 1994.

[14] M. S. Sunitha and A. V. Kumar, "Complement of a fuzzy graph," Indian Journal of Pure and Applied Mathematics, vol. 33, no. 9, pp. 1451-1464, 2002.

[15] H. Ju and L. Wang, "Interval-valued fuzzy subsemigroups and subgroups associated by intervalvalued fuzzy graphs," in Proceedings of the WRI Global Congress on Intelligent Systems (GCIS '09), pp. 484-487, Xiamen, China, May 2009.

[16] M. Akram, "Bipolar fuzzy graphs," Information Sciences, vol. 181, no. 24, pp. 5548-5564, 2011.

[17] M. Akram, "Bipolar fuzzy graphs with applications," Knowledge Based Systems, vol. 39, pp. 1-8, 2013.

[18] M. Akram, "Interval-valued fuzzy line graphs," Neural Computing and Applications, vol. 21, pp. 145-150, 2012.

[19] M. Akram and W. A. Dudek, "Interval-valued fuzzy graphs," Computers \& Mathematics with Applications, vol. 61, no. 2, pp. 289-299, 2011.

[20] M. Akram and B. Davvaz, "Strong intuitionistic fuzzy graphs," Filomat, vol. 26, no. 1, pp. 177-196, 2012.

[21] M. Akram, K. H. Dar, and K. P. Shum, "Interval-valued $(\alpha, \beta)$ fuzzy K-algebras," Applied Soft Computing Journal, vol. 11, no. 1, pp. 1213-1222, 2011.

[22] T. AL-Hawary, "Complete fuzzy graphs," International Journal of Mathematical Combinatorics, vol. 4, pp. 26-34, 2011.

[23] P. Bhattacharya, "Some remarks on fuzzy graphs," Pattern Recognition Letters, vol. 6, no. 5, pp. 297-302, 1987.

[24] S. M. Chen, "Interval-valued fuzzy hypergraph and fuzzy partition," IEEE Transactions on Systems, Man, and Cybernetics $B$, vol. 27, no. 4, pp. 725-733, 1997.
[25] G. Deschrijver and C. Cornelis, "Representability in intervalvalued fuzzy set theory," International Journal of Uncertainty, Fuzziness and Knowledge-Based Systems, vol. 15, no. 3, pp. 345361, 2007.

[26] A. N. Gani and S. R. Latha, “On irregular fuzzy graphs," Applied Mathematical Sciences, vol. 6, no. 9-12, pp. 517-523, 2012.

[27] X. Ma, J. Zhan, B. Davvaz, and Y. B. Jun, "Some kinds of $(\epsilon, \epsilon$ $\vee q$ )-interval-valued fuzzy ideals of BCI-algebras," Information Sciences, vol. 178, no. 19, pp. 3738-3754, 2008.

[28] J. N. Mordeson and P. S. Nair, Fuzzy Graphs and Fuzzy Hypergraphs, Studies in Fuzziness and Soft Computing, Physica, Heidelberg, Germany, 1998.

[29] F. Riaz and K. M. Ali, "Applications of graph theory in computer science," in Proceedings of the 3rd International Conference on Computational Intelligence, Communication Systems and Networks (CICSyN '11), pp. 142-145, Bali, Indonesia, July 2011.

[30] M. Behzad and G. Chartrand, "No graph is perfect," The American Mathematical Monthly, vol. 74, pp. 962-963, 1967.

[31] G. Deschrijver and E. E. Kerre, "On the relationship between some extensions of fuzzy set theory," Fuzzy Sets and Systems, vol. 133, no. 2, pp. 227-235, 2003.

[32] A. Shannon and K. T. Atanassov, "A first step to a theory of the intuitionistic fuzzy graphs," in Proceeding of the FUBEST, D. Lakov, Ed., pp. 59-61, Sofia, Bulgaria, 1994.

[33] R. Parvathi, M. G. Karunambigai, and K. T. Atanassov, "Operations on intuitionistic fuzzy graphs," in Proceedings of the IEEE International Conference on Fuzzy Systems, pp. 1396-1401, August 2009. 


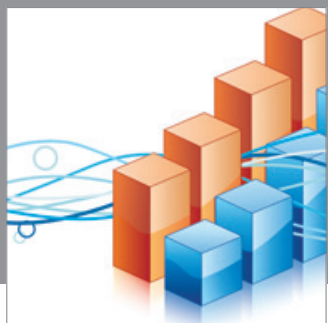

Advances in

Operations Research

mansans

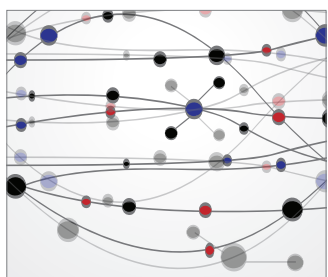

The Scientific World Journal
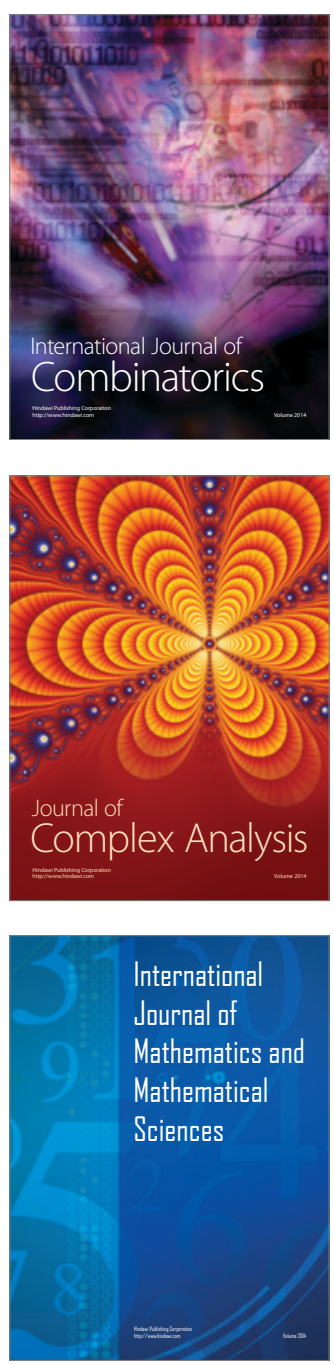
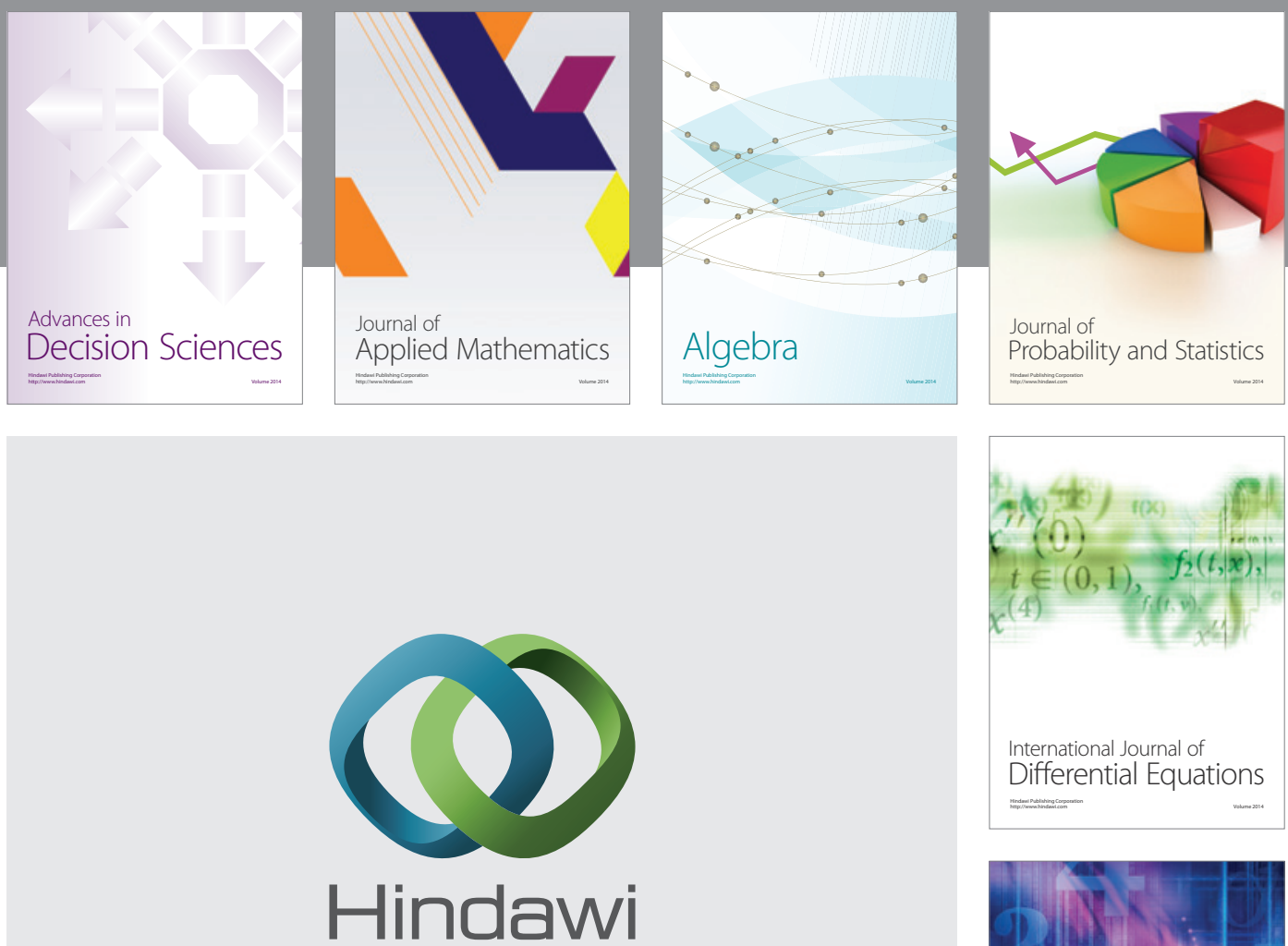

Submit your manuscripts at http://www.hindawi.com
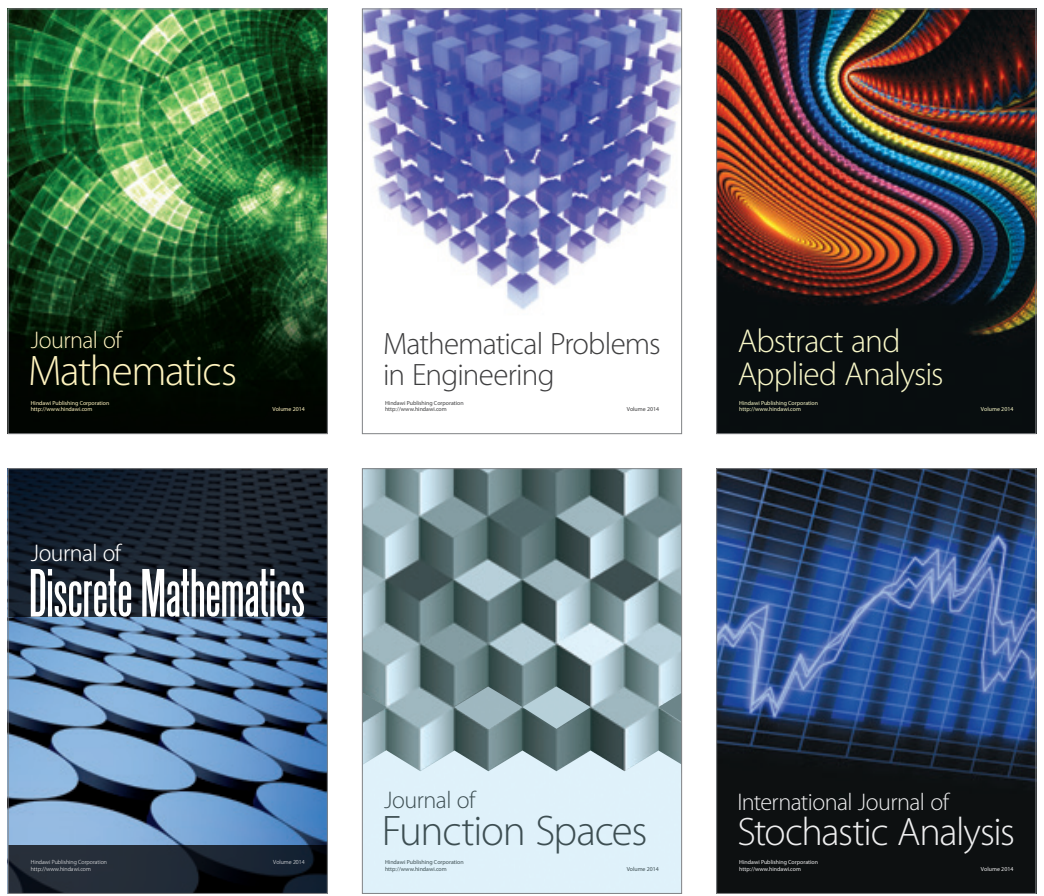

Journal of

Function Spaces

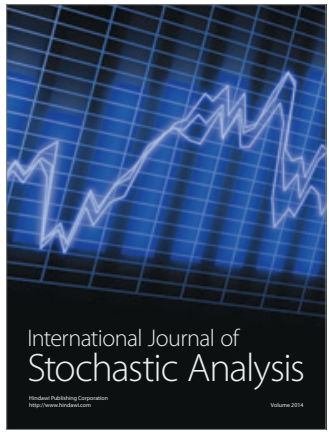

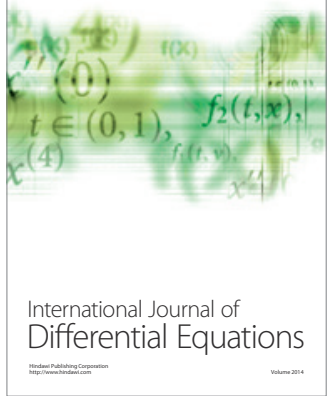
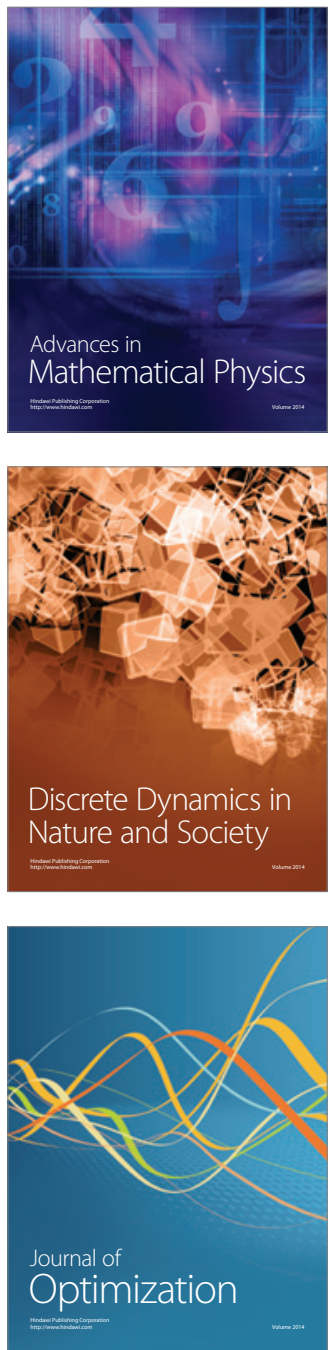